Check for updates

Cite this: J. Mater. Chem. A, 2019, 7, 21264

Received 19th June 2019

Accepted 25th August 2019

DOI: $10.1039 /$ c9ta06593h

rsc.li/materials-a

\section{Layered cobalt hydrotalcite as an advanced lithium-ion anode material with high capacity and rate capability $\dagger$}

\begin{abstract}
Long Pan, (D) * Haijian Huang (D) and Markus Niederberger (D)
Lithium-ion anode materials with high energy density and high power density are growing in demand for practical applications. However, conventional electrode materials such as graphite and lithium titanium oxide (LTO) cannot meet these requirements. Here, we report layered cobalt hydrotalcite (LCH) as an advanced anode material for lithium-ion batteries with high capacity and rate capability. The large interlayer distance of the LCH structure offers sufficient space for lithium-ion insertion, which is demonstrated using various electrochemical analyses, operando X-ray diffraction, and ex situ X-ray photoelectron spectroscopy. Owing to the fast lithium-ion insertion kinetics and the unique 2D morphology, the LCH exhibits a high reversible capacity of 743.9 and $643.4 \mathrm{~mA} \mathrm{~h} \mathrm{~g}$ at 500 and $2000 \mathrm{~mA} \mathrm{~g}^{-1}$ over 600 and 2000 cycles, respectively, and an outstanding rate capability (490.0 $\mathrm{mA} \mathrm{h} \mathrm{g}^{-1}$ at $5000 \mathrm{~mA} \mathrm{~g}^{-1}$ ) in lithium-ion half cells. This excellent electrochemical performance makes LCH a promising alternative to the currently existing pseudocapacitive materials as an anode for lithium-ion batteries.
\end{abstract}

\section{Introduction}

Currently, lithium-ion batteries (LIBs) are widely used in portable electronic devices and electric vehicles. With the evergrowing demand for energy and power density, LIBs with the conventional anode material, i.e., graphite (theoretical capacity $=372 \mathrm{~mA} \mathrm{~h} \mathrm{~g}^{-1}$ ), have reached their limit. ${ }^{1}$ Therefore, great efforts are being made to discover alternative anode materials with higher capacity and better rate capability. Transition metal oxides/sulfides (e.g., $\mathrm{Fe}_{3} \mathrm{O}_{4}, \mathrm{Mn}_{3} \mathrm{O}_{4}$, and $\mathrm{MoS}_{2}$ ) with a conversion mechanism and elementary substances (e.g., $\mathrm{Si}, \mathrm{P}, \mathrm{Sn}$, and $\mathrm{Ge}$ ) with an alloying mechanism have been proposed due to their high theoretical capacities. ${ }^{2-12}$ However, these materials always suffer from sluggish rate capabilities because of their low conductivity. ${ }^{6,8}$ Recently, new types of anode materials such as $\mathrm{Nb}_{2} \mathrm{O}_{5}$ and $\mathrm{TiO}_{2}(\mathrm{~B})$ have been explored as high-rate anode materials, despite their low electrical conductivity. ${ }^{11,13-15}$ These hosts exhibit a unique $\mathrm{Li}^{+}$storage mechanism, i.e., pseudocapacitance, thereby offering fast $\mathrm{Li}^{+}$insertion/extraction. ${ }^{15,16}$ Unfortunately, such materials deliver relatively low theoretical capacity (e.g., $\mathrm{Nb}_{2} \mathrm{O}_{5}$ vs. graphite, $200 v s .372 \mathrm{~mA} \mathrm{~h} \mathrm{~g}^{-1}$ ), which hinders their practical application in next-generation, highenergy LIBs. ${ }^{15,16}$ Therefore, it is particularly urgent to pursue an advanced host with high capacity and high rate $\mathrm{Li}^{+}$storage.

Department of Materials, Laboratory for Multifunctional Materials, ETH Zurich, Vladimir-Prelog-Weg 5, 8093, Zurich, Switzerland. E-mail: long.pan@mat.ethz.ch

$\dagger$ Electronic supplementary information (ESI) available: Supplementary figures and tables. See DOI: 10.1039/c9ta06593h
Hydrotalcite is a layered material with anions (e.g., $\mathrm{NO}_{3}{ }^{-}$and $\mathrm{CO}_{3}{ }^{2-}$ ) located in the interlayer voids. ${ }^{17}$ It has attracted much interest in the field of supercapacitors and aqueous alkaline batteries because of the possibility of adjusting the metal cations and the intercalating anions. ${ }^{18-20}$ Additionally, hydrotalcite exhibits flexible and large interlayer spacing, which is supposed to be a favorable structure for alkali-ion intercalation electrode materials. ${ }^{21}$ In spite of these promising characteristics, however, neither the $\mathrm{Li}^{+}$storage property nor its mechanism has been investigated for hydrotalcite.

Here, we demonstrate the suitability of layered cobalt hydrotalcite $(\mathrm{LCH})$ as a conversion-type $\mathrm{Li}^{+}$storage anode material with high capacity and high rate capability via various electrochemical analyses, operando powder X-ray diffraction (XRD), and ex situ X-ray photoelectron spectroscopy (XPS). It is confirmed that the layered structure with large interlayer spacing offers unique diffusion pathways for fast $\mathrm{Li}^{+}$storage. These merits, together with the small surface area, endow the LCH with a high reversible capacity of $1369.5 \mathrm{~mA} \mathrm{~h} \mathrm{~g}^{-1}$ at $100 \mathrm{~mA} \mathrm{~g}^{-1}$ in the first cycle. In addition, the LCH exhibits a good cycling performance, e.g., $743.9 \mathrm{~mA} \mathrm{~h} \mathrm{~g}^{-1}$ at $500 \mathrm{~mA} \mathrm{~g}^{-1}$ after 600 cycles and $643.4 \mathrm{~mA} \mathrm{~h} \mathrm{~g}^{-1}$ at $2000 \mathrm{~mA} \mathrm{~g}^{-1}$ over 2000 cycles, and an outstanding rate capability $\left(490.0 \mathrm{~mA} \mathrm{~h} \mathrm{~g}^{-1}\right.$ at $5000 \mathrm{~mA} \mathrm{~g}^{-1}$ ).

\section{Results and discussion}

The LCH nanosheets were synthesized from $\mathrm{Co}\left(\mathrm{NO}_{3}\right)_{2} \cdot 6 \mathrm{H}_{2} \mathrm{O}$ with the assistance of microwave radiation. LCH has been 
widely studied over the last several decades. ${ }^{17,22}$ The general chemical formula of $\mathrm{LCH}$ is proposed to be $\mathrm{Co}(\mathrm{OH})_{1.5}\left(\mathrm{NO}_{3}\right)_{0.5},{ }^{22}$ where the $-\mathrm{OH}$ groups are covalently bound to $\mathrm{Co}^{2+}$, forming octahedral $\mathrm{Co}(\mathrm{OH})_{1.5}$ units, and where the $\mathrm{NO}_{3}{ }^{-}$anions are intercalated in between the layers, as shown in Fig. 1a and S1 (ESI $\dagger$ ). The interlayer spacing of LCHs is about $6.96 \AA$, which is much larger than the radius of $\mathrm{Li}^{+}(0.76 \AA)$, enabling fast $\mathrm{Li}^{+}$ diffusion. ${ }^{22,23}$ The nanosheet morphology of the $\mathrm{LCH}$ is revealed by scanning electron microscopy (SEM) and transmission electron microscopy (TEM), as shown in Fig. 1b, c and S2 (ESI $\dagger$ ). The $\mathrm{LCH}$ nanosheets are of hexagonal shape and their lateral sizes are in the range of several microns. According to the highresolution TEM (HRTEM) image (Fig. 1d), the LCH nanosheets are composed of a layered structure with an interlayer distance of $7.0 \AA$. Apart from the high crystallinity (Fig. S3, $\mathrm{ESI}^{\dagger}$ ), the individual LCH nanosheets are single crystalline as revealed by the well-developed spots in the selected area electron diffraction (SAED) pattern (Fig. 1e). The scanning TEM (STEM) together with the element mapping analysis (Fig. 1f) shows the homogeneous distribution of Co, $\mathrm{O}$, and $\mathrm{N}$ throughout the $\mathrm{LCH}$ nanosheets, confirming the presence of $\mathrm{NO}_{3}{ }^{-}$in the $\mathrm{LCH}$ structure.

The crystal structure and the phase of the LCH nanosheets are disclosed by XRD, as depicted in Fig. 1g. The XRD pattern exhibits two intensive peaks corresponding to the (001) and (002) reflections of a typical layered structure. ${ }^{22}$ The calculated interlayer spacing from the (001) plane is $6.97 \AA$, which is in good agreement with the HRTEM result (Fig. 1d) and the crystal structure in Fig. 1a. Fig. S4 (ESI $\dagger$ ) displays the XPS survey spectrum, in which well-resolved Co 2p, N 1s, and $\mathrm{O}$ 1s peaks are observed. Besides, the atomic ratio of $\mathrm{Co}, \mathrm{N}$, and $\mathrm{O}$ obtained from XPS analysis (Table S1, ESI $\dagger$ ) agrees well with the theoretical ratio, indicating that the chemical formula of $\mathrm{LCH}$ is indeed $\mathrm{Co}(\mathrm{OH})_{1.5}\left(\mathrm{NO}_{3}\right)_{0.5}$. The high-resolution Co 2p spectrum in Fig. 1h shows two well-resolved peaks at 781.06 and $797.28 \mathrm{eV}$, corresponding to the $2 \mathrm{p}_{3 / 2}$ and $2 \mathrm{p}_{1 / 2}$ orbitals of $\mathrm{Co}^{2+}$. Two additional broad peaks at 786.68 and $803.08 \mathrm{eV}$ can be assigned to satellite features of $\mathrm{Co}^{2+} \cdot{ }^{24}$ These results together with the asymmetrical shape of the Co 2 p peaks imply that the Co cations in the $\mathrm{LCH}$ nanosheets are divalent $\left(\mathrm{Co}^{2+}\right)$. The prominent peak at $407.04 \mathrm{eV}$ in the $\mathrm{N}$ 1s spectrum (Fig. 1i) fits to $\mathrm{NO}_{3}{ }^{-}$, once again indicating the presence of $\mathrm{NO}_{3}{ }^{-}$in the $\mathrm{LCH}$ nanosheets. ${ }^{22}$ The small, broad peak located at $399.22 \mathrm{eV}$ can be related to $-\mathrm{NH}_{2}$, presumably as a result of oleylamine residues. ${ }^{25}$ The very small amount of $-\mathrm{NH}_{2}$ groups, therefore, has little influence on the compositional analysis of the XPS results. Besides, the presence of $-\mathrm{OH}$ and $\mathrm{NO}_{3}{ }^{-}$is further confirmed by the $\mathrm{O} 1 \mathrm{~s}$ spectrum, as shown in Fig. $1 \mathrm{j}$.

To explore the $\mathrm{Li}^{+}$storage properties of the $\mathrm{LCH}$ nanosheets, galvanostatic tests using a half cell with lithium foil as the counter electrode were performed. Fig. 2a shows the first discharging-charging curves of the LCH anode at a specific current of $100 \mathrm{~mA} \mathrm{~g}^{-1}$. During the first discharge, an obvious plateau around $1.0 \mathrm{~V}$ is observed, which may be attributed to the $\mathrm{Li}^{+}$
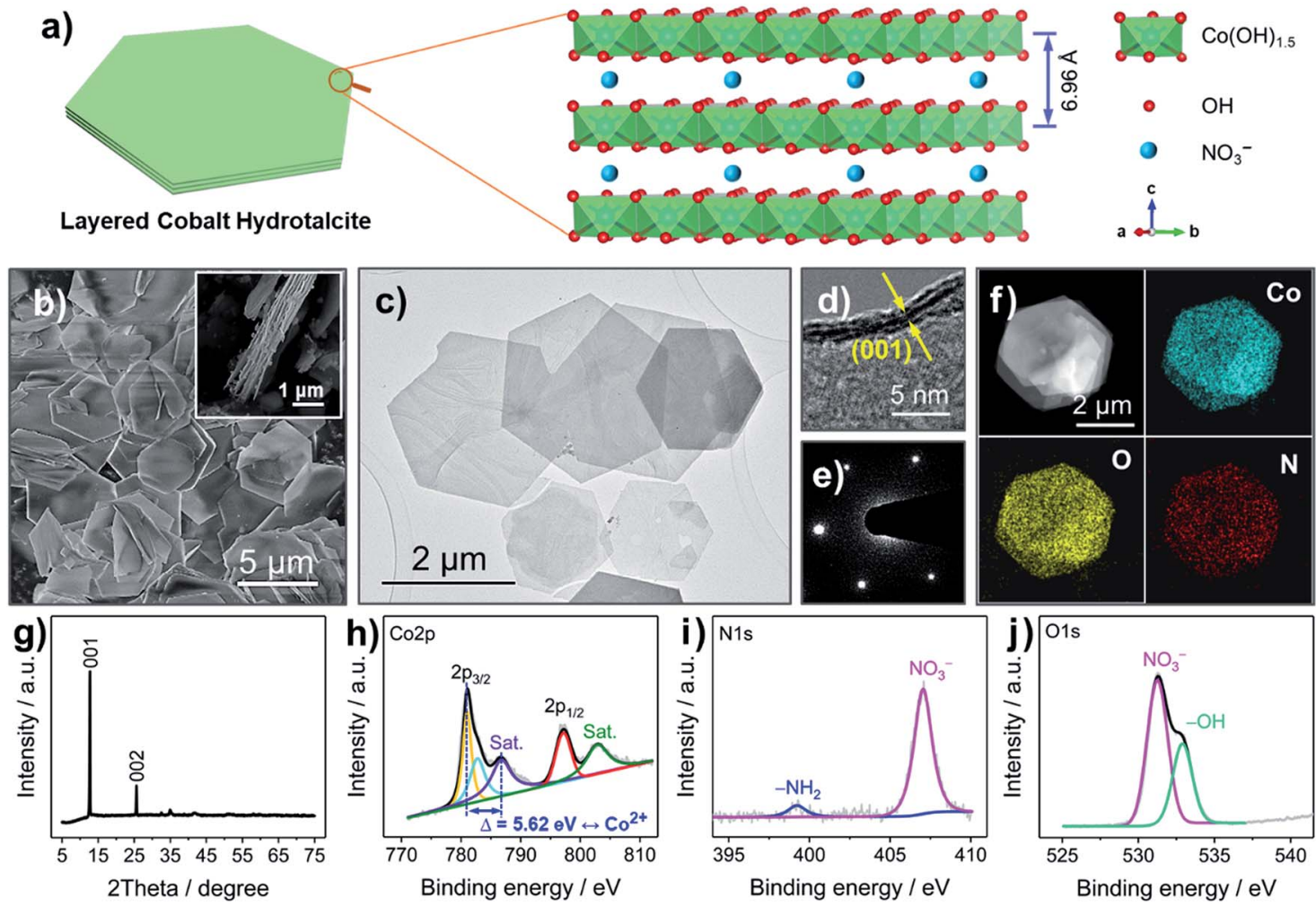

Fig. 1 Characterization of the LCH nanosheets. (a) Schematic illustration of the LCH nanosheets and the crystal structure (hexagonal symmetry). (b) SEM, (c) TEM, (d) HRTEM, (e) SAED, and (f) STEM with elemental mapping images of the LCH nanosheets. (g) XRD pattern, and (h) Co 2p, (i) N 1s, and (j) $O$ 1s XPS spectra of the LCH nanosheets. 

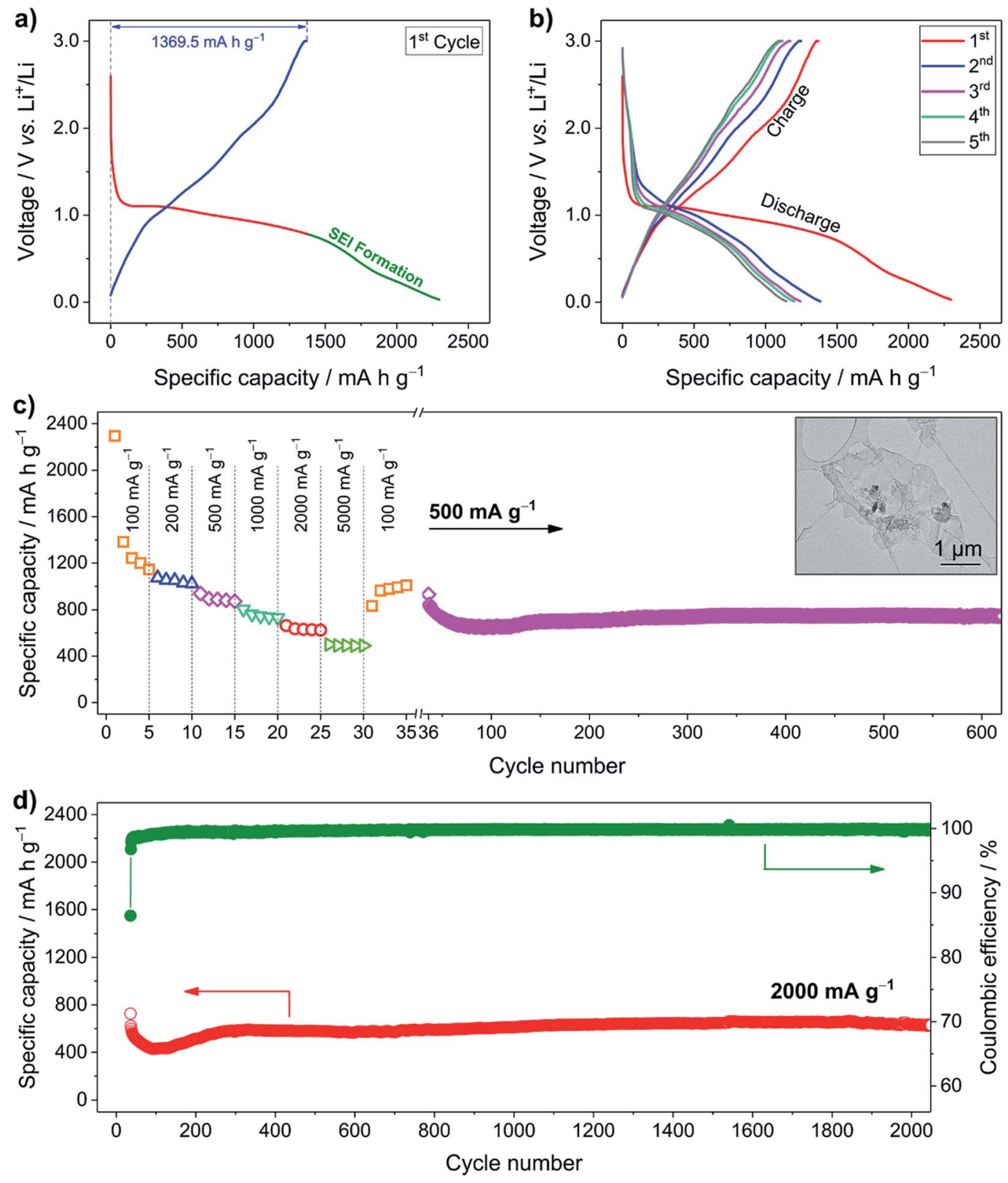

Fig. 2 Electrochemical performance of the LCH nanosheets. (a) First and (b) first five discharging-charging curves of the LCH nanosheets (specific current $=100 \mathrm{~mA} \mathrm{~g}^{-1}$ ). (c) Rate capability and cycling performance of the $\mathrm{LCH}$ nanosheets. (d) Long-term cyclability of the LCH nanosheets (specific current $=2000 \mathrm{~mA} \mathrm{~g}^{-1}$ ). The inset in (c) shows a TEM image of the LCH nanosheets after 600 cycles at $500 \mathrm{~mA} \mathrm{~g}^{-1}$.

reaction with the $\mathrm{LCH}$. After discharging to $0.8 \mathrm{~V}$, the solidelectrolyte interphase (SEI) starts to form and electrochemically activated electrolyte decomposition occurs. ${ }^{26}$ In total, the specific capacity of the first discharge is $2296.7 \mathrm{~mA} \mathrm{~h} \mathrm{~g}^{-1}$. During the charging process, $\mathrm{Li}^{+}$is extracted from the $\mathrm{LCH}$, delivering a reversible capacity of $1369.5 \mathrm{~mA} \mathrm{~h} \mathrm{~g}^{-1}$ (3.7 times that of graphite). Therefore, the coulombic efficiency of the first cycle is about $60 \%$. This value is comparable to or even higher than that of $\mathrm{Co}(\mathrm{OH})_{2}$-based electrode materials, indicating the favorable kinetics of $\mathrm{Li}^{+}$storage in $\mathrm{LCH} .{ }^{27,28}$ Another reason for this high value is that the small specific surface area of the $\mathrm{LCH}$ (6.7 $\mathrm{m}^{2} \mathrm{~g}^{-1}$ shown in Fig. S5, ESI $\dagger$ ) brings along fewer irreversible side reactions from the electrolyte decomposition compared to those having large surface area. ${ }^{29}$ Thanks to the SEI layer, the coulombic efficiency increases to $90 \%$ in the second cycle and further rises to $97 \%$ in the fifth cycle, as displayed in Fig. 2b. The $\mathrm{Li}^{+}$storage behavior is also examined by cyclic voltammetry (CV) (Fig. S6, ESI $\dagger$ ), which confirms the results from the galvanostatic tests.

The good rate capability of the LCH anode material is presented in Fig. 2c. In the first five cycles, a high reversible capacity of $1144.5 \mathrm{~mA} \mathrm{~h} \mathrm{~g}^{-1}$ at a specific current of $100 \mathrm{~mA} \mathrm{~g}^{-1}$ is delivered. Then, the specific current is gradually increased to $200,500,1000$, and $2000 \mathrm{~mA} \mathrm{~g}^{-1}$ with five cycles for each rate, 

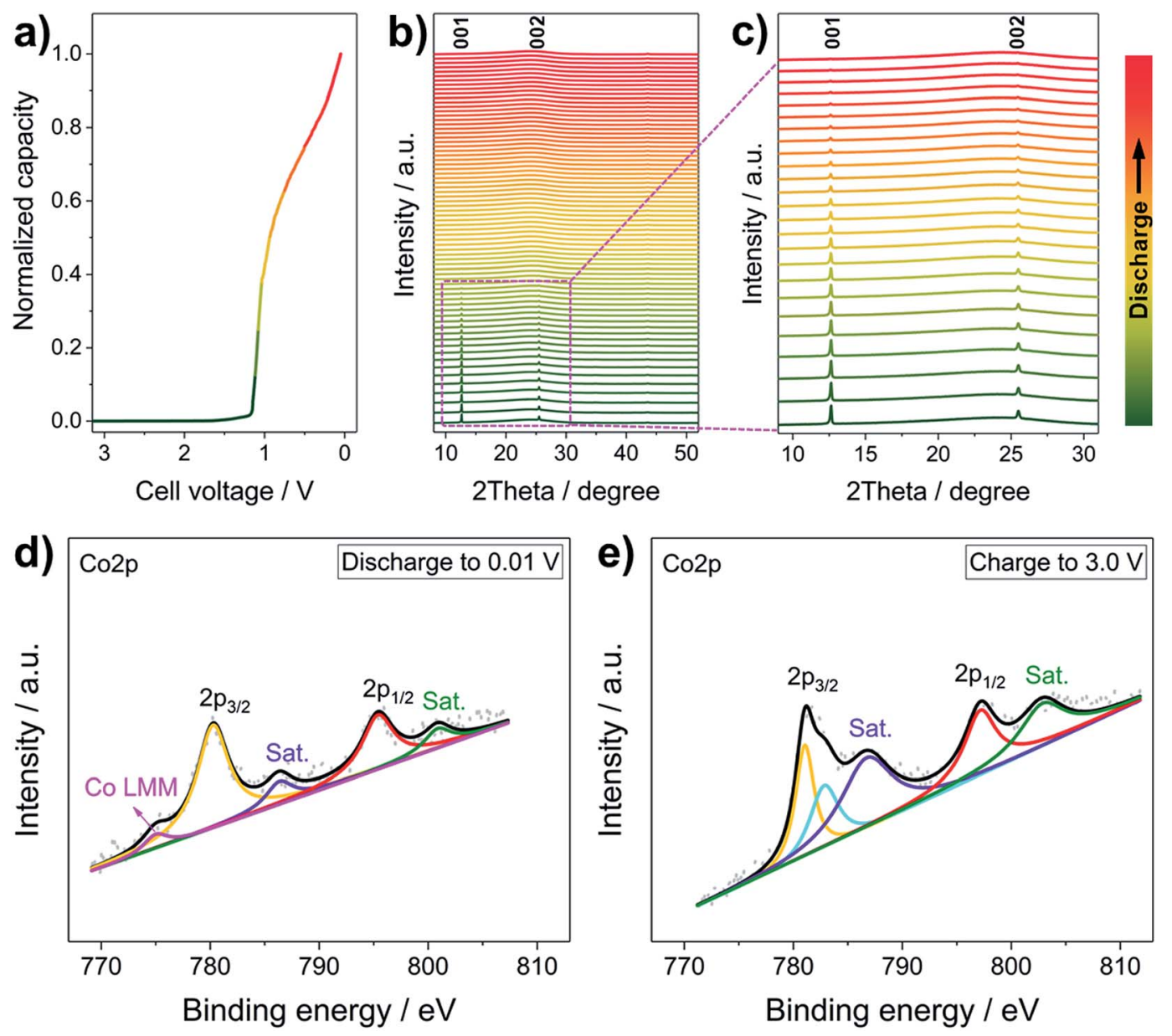

Fig. 3 Investigation of the $\mathrm{Li}^{+}$storage mechanism of the $\mathrm{LCH}$ nanosheets. (a) The first discharging profile $\left(50 \mathrm{~mA} \mathrm{~g}{ }^{-1}\right)$ and $(\mathrm{b}$ and $\mathrm{c})$ corresponding operando XRD patterns. High-resolution Co 2p XPS spectra of the LCH nanosheets (d) discharged to $0.01 \mathrm{~V}$ and (e) charged to $3.0 \mathrm{~V}$.

resulting in a reversible capacity of 1022.0, 872.4, 730.5, and $624.4 \mathrm{~mA} \mathrm{~h} \mathrm{~g}^{-1}$, respectively. Even at a specific current as high

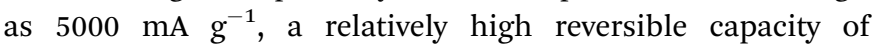
$490.0 \mathrm{~mA} \mathrm{~h} \mathrm{~g}^{-1}$ is delivered. The LCH anode material is further tested at $500 \mathrm{~mA} \mathrm{~g}^{-1}$ over 600 cycles to analyze its cycling performance. It delivers a reversible capacity of $743.9 \mathrm{~mA} \mathrm{~h} \mathrm{~g}^{-1}$, which is almost two times that of graphite. After 600 cycles, the nanosheet-like morphology of the LCH is mainly retained, despite the partial fracture of the pristine hexagonal nanosheets, as displayed in the inset of Fig. 2c. The long-term cycling performance is further investigated at a specific current of $2000 \mathrm{~mA} \mathrm{~g}^{-1}$ over 2000 cycles (Fig. 2d). A reversible capacity as high as $643.4 \mathrm{~mA} \mathrm{~h} \mathrm{~g}{ }^{-1}$ is delivered, indicating outstanding cyclability of the LCH anode material. Even compared to the typical conversion-type anode materials such as $\mathrm{Co}_{3} \mathrm{O}_{4}$ and $\mathrm{Fe}_{3} \mathrm{O}_{4}$ (Table S2 and Fig. S7, ESI + ), the LCH still exhibits comparable or even better cyclability and rate capability, indicating its great potential for high-performance $\mathrm{Li}^{+}$storage applications. As seen from the cycling curves in both Fig. $2 \mathrm{c}$ and $\mathrm{d}$, the capacities gradually increase in the beginning and then become stable, which is common in cobalt-containing electrode materials. ${ }^{30-34}$ Several reasons have been proposed to explain this phenomenon, including a reversible growth of a polymer gel-like layer and gradual wetting of electrode materials by the electrolyte..$^{33,35}$ Besides these reasons, in our case, another possible explanation is the gradual $\mathrm{Li}^{+}$reaction with electrode materials at high specific current, as discussed later.

To uncover the $\mathrm{Li}^{+}$storage mechanism of the $\mathrm{LCH}$, operando XRD and ex situ high-resolution XPS were performed. Generally, when $\mathrm{Li}^{+}$is inserted in conversion type $\left(\right.$e.g., $\left.\mathrm{Co}_{3} \mathrm{O}_{4}\right)$ or alloying type (e.g., Sn) anode materials, they transform to materials with crystal structures that are totally different from the original ones (e.g., $\mathrm{Co}_{3} \mathrm{O}_{4}+8 \mathrm{Li}^{+}+8 \mathrm{e}^{-} \rightarrow 3 \mathrm{Co}+4 \mathrm{Li}_{2} \mathrm{O}, \mathrm{Sn}+x \mathrm{Li}^{+}+x \mathrm{e}^{-} \rightarrow$ $\left.\mathrm{Li}_{x} \mathrm{Sn}\right){ }^{30,36}$ Therefore, new characteristic peaks corresponding to these phases are expected to appear during the operando XRD measurements. ${ }^{37}$ In some cases, however, the newly formed products are amorphous, meaning that all peaks disappear. ${ }^{38}$ Fig. 3a-c present the operando XRD patterns and the corresponding discharging curve of the first discharging of the $\mathrm{LCH}$. During the $\mathrm{Li}^{+}$reaction at a relatively low specific current of $50 \mathrm{~mA} \mathrm{~g}^{-1}$ (Fig. 3a), all peaks of the LCH structure gradually disappear, and no new peaks except a broad one located at $25^{\circ}$ are observed in all patterns (Fig. $3 \mathrm{~b}$ and c). We stress that the $25^{\circ}$ peak comes from the background of the operando cell, 
which is proved in Fig. S8 (ESI $\dagger$ ). Besides, the characteristic reflections of LCH do not appear after charging to $3.0 \mathrm{~V}$ (Fig. S9, ESI $\dagger$ ), which is similar to other conversion type anode materials. ${ }^{38}$ These results confirm a conversion or alloying type mechanism for the $\mathrm{LCH} .{ }^{38}$ Generally, conversion mechanisms occur in compounds, whereas alloying reactions take place in elementary substances. ${ }^{2-12}$ Therefore, it can be inferred that the $\mathrm{LCH}$ goes through a conversion reaction with $\mathrm{Li}^{+}$. Also, we recorded the operando XRD patterns at a high discharging/ charging specific current $\left(200 \mathrm{~mA} \mathrm{~g}^{-1}\right)$, as shown in Fig. S10 $(\mathrm{ESI} \dagger)$. Similarly, the intensities of the $(00 l)$ reflections gradually decrease and no new peaks appear during the discharge. Note that the $(00 l)$ reflections are still observable after several cycles, indicating that the $\mathrm{LCH}$ does not fully react with $\mathrm{Li}^{+}$in the first few cycles because of the high specific current. As the cycling goes on, more and more LCH is converted, resulting in a steady decrease of reflection intensities and a gradual increase of specific capacity. After complete conversion of $\mathrm{LCH}$, the specific capacity becomes stable (Fig. 2c and d). These results demonstrate that the specific current does not change the $\mathrm{Li}^{+}$storage mechanism but affects the reaction degree of $\mathrm{Li}^{+}$with electrode materials.

Further confirmation of the conversion mechanism is revealed by ex situ XPS characterization. The high-resolution Co $2 \mathrm{p}$ XPS spectra at different discharging and charging states are presented in Fig. $3 \mathrm{~d}$ and e, respectively. Generally, the Co $2 \mathrm{p}_{3 / 2}$ orbital of metallic Co exhibits an asymmetric peak at $\sim 778.1 \mathrm{eV}$ with a loss satellite feature and a weak Co LMM Auger peak. ${ }^{39,40}$ In this case, however, the asymmetric Co $2 \mathrm{p}_{3 / 2}$ peak of pristine LCH (Fig. 1h) turns to be semi-asymmetric (Fig. 3d) after discharging to $0.01 \mathrm{~V}$. The Co $2 \mathrm{p}_{3 / 2}$ binding energy of the discharged $\mathrm{LCH}$ is $780.42 \mathrm{eV}$, which is higher than that of metallic Co but lower than that of $\mathrm{Co}^{2+}$. Besides, two weak satellite peaks and a small Co LMM Auger peak are witnessed, indicating that the $\mathrm{LCH}$ is reduced to metallic Co during $\mathrm{Li}^{+}$uptake. Note that the semi-asymmetric peak, the higher binding energy and the weak satellite peaks may come from a small amount of unreacted LCH at a relatively high specific current, which is in good agreement with the operando results (Fig. S10, ESI $\dagger$ ). After charging to $3.0 \mathrm{~V}$, the Co $2 \mathrm{p}$ spectrum of the $\mathrm{LCH}$ (Fig. 3e) is almost the same as that of the pristine LCH (Fig. 1h), implying a highly reversible $\mathrm{Li}^{+}$storage behavior of $\mathrm{LCH}$. On the basis of the operando XRD and ex situ XPS results, the $\mathrm{Li}^{+}$storage mechanism in $\mathrm{LCH}$ is demonstrated to follow a conversion process, in which $\mathrm{LCH}$ is converted to metallic Co. It should be pointed out that the role of $\mathrm{NO}_{3}{ }^{-}$anions in the $\mathrm{Li}^{+}$storage property is not clear yet, which will be systematically investigated in the future work.

\section{Conclusions}

In this work we show that $\mathrm{LCH}$ is a promising conversion-type $\mathrm{Li}^{+}$anode material with high capacity and high rate capability. Various electrochemical analyses were performed, including operando XRD measurement and ex situ XPS characterization. These results demonstrate the conversion mechanism of the $\mathrm{LCH}$. Owing to the unique 2D morphology with large interlayer spacing and fast ion-storage kinetics, the LCH exhibits excellent cycling stability at high specific current and good rate performance, satisfying the high requirements of next-generation, high-performance LIBs. Note that there are still some problems remaining for conversion-type anode materials such as voltage drops arising from the multiphase nature of the reaction, which should be addressed toward practical applications. Our work introduces a new class of potential electrode materials, paving the way for discovering other layered hydrotalcites for high energy and high power metal-ion batteries.

\section{Experimental}

\section{Materials}

$\mathrm{Co}\left(\mathrm{NO}_{3}\right)_{2} \cdot 6 \mathrm{H}_{2} \mathrm{O}(\geq 99.0 \%$ ), oleic acid (technical grade, 90\%), benzyl alcohol (99-100.5\%), and chloroform ( $\geq 99.8 \%)$ were purchased from Sigma-Aldrich. Tetrahydrofuran and acetone were purchased from VWR Chemicals. Oleylamine (C18 content 80-90\%) and carboxymethylcellulose sodium salt (CMC, DS = 0.9 , M.W. $=700000 \mathrm{~g} \mathrm{~mol}^{-1}$ ) were purchased from Acros Organics. All chemicals were used as received.

\section{Synthesis of LCH nanosheets}

Typically, $5 \mathrm{mmol}$ of $\mathrm{Co}\left(\mathrm{NO}_{3}\right)_{2} \cdot 6 \mathrm{H}_{2} \mathrm{O}, 25 \mathrm{mmol}$ of oleylamine, $25 \mathrm{mmol}$ of oleic acid, and $42.6 \mathrm{mmol}$ of benzyl alcohol were mixed in a $35 \mathrm{~mL}$ microwave tube. The mixture was subjected to a microwave reactor (Discover SP, CEM) at $180{ }^{\circ} \mathrm{C}$ for $20 \mathrm{~min}$. After cooling down, the product was washed with acetone (2 times), chloroform (2 times), tetrahydrofuran (2 times), and acetone ( 2 times). Finally, the LCH nanosheets were obtained by vacuum drying at $50{ }^{\circ} \mathrm{C}$ overnight.

\section{Electrochemical tests}

LCH nanosheets (active materials), carbon black (conductive additive), and CMC (binder) were mixed with deionized water at a ratio of $60: 30: 10 \mathrm{wt} \%$. After mixing in a ball mill (Mixer Mill MM 400, Retsch) at $20 \mathrm{~Hz}$ for $20 \mathrm{~min}$, the homogeneous slurry was coated on a titanium holder (current collector) and vacuumdried. Half-cells with lithium foil as the counter electrodes were assembled. $1 \mathrm{M} \mathrm{LiPF}_{6}$ solution in dimethyl carbonate/ethylene carbonate (volume ratio, 1/1) was used as the electrolyte. Glass fiber membranes (GF/D, Whatman) were used as separators. The mass loading of the active material is about $1 \mathrm{mg}$ $\mathrm{cm}^{-2}$. Note that the relatively high content of carbon black was added to ensure sufficient conductivity of LCH. Besides, the capacity contribution of carbon black to the total capacity is small ( 8\%), as shown in Fig. S11 (ESI $\dagger$ ).

\section{Characterization}

TEM and SAED measurements were performed on a Hitachi HT7700 microscope at an accelerating voltage of $100 \mathrm{kV}$ or on an FEI Tecnai F30 FEG microscope at an accelerating voltage of $300 \mathrm{kV}$. For STEM and HRTEM measurements we used an FEI Talos F 200X microscope at an accelerating voltage of $200 \mathrm{kV}$. SEM data were acquired on a ZEISS LEO 1530 microscope at an accelerating voltage of $5 \mathrm{kV}$. XPS experiments were carried out 
on an Escalab 250 Xi spectrometer or a Thermo scientific Sigma 2 spectrometer. XRD measurements were performed on a PANalytical Empyrean X-ray diffractometer with $\mathrm{Cu} \mathrm{K} \alpha$ radiation $(\lambda$ $=0.154 \mathrm{~nm}$ ). The specific surface area was calculated according to the Brunauer-Emmett-Teller (BET) method based on nitrogen adsorption data from a Quantachrome Autosorb iQ analyzer.

\section{Conflicts of interest}

There are no conflicts to declare.

\section{Acknowledgements}

The authors thank Dr E. Tervoort and Dr F. Gramm for TEM characterization and discussions, Prof. A. Studart for providing the SEM equipment, Prof. A. Rossi and G. Cossu for providing the XPS equipment, the Scientific Center for Optical and Electron Microscopy (ScopeM) of ETH Zürich for access to TEM facilities, and Dr D. Kundu for helpful discussions. The authors acknowledge financial support from ETH Zürich. L. P. is grateful for the fellowship from the Office of China Postdoctoral Council (No. 32 Document of OCPC, 2017). H. H. acknowledges the financial support from the China Scholarship Council.

\section{Notes and references}

1 N. Mahmood, T. Tang and Y. Hou, Adv. Energy Mater., 2016, 6, 1600374.

2 L. Pan, Y.-T. Liu, X.-M. Xie and X.-D. Zhu, Chem.-Asian J., 2014, 9, 1519.

3 L. Pan, K.-X. Wang, X.-D. Zhu, X.-M. Xie and Y.-T. Liu, J. Mater. Chem. A, 2015, 3, 6477.

4 Y. M. Chen, X. Y. Yu, Z. Li, U. Paik and X. W. Lou, Sci. Adv., 2016, 2, e1600021.

5 L. Pan, X.-D. Zhu, X.-M. Xie and Y.-T. Liu, J. Mater. Chem. A, 2015, 3, 2726.

6 D. Bresser, S. Passerini and B. Scrosati, Energy Environ. Sci., 2016, 9, 3348.

7 L. Pan, X.-D. Zhu, K.-N. Sun, Y.-T. Liu, X.-M. Xie and X.-Y. Ye, Nano Energy, 2016, 30, 347.

8 Y. Lu, L. Yu and X. W. Lou, Chem, 2018, 4, 972.

9 L. Pan, Y.-T. Liu, X.-M. Xie and X.-Y. Ye, Small, 2016, 12, 6703.

10 L. Pan, X.-D. Zhu, X.-M. Xie and Y.-T. Liu, Adv. Funct. Mater., 2015, 25, 3341.

11 B. Y. Guan, L. Yu, J. Li and X. W. Lou, Sci. Adv., 2016, 2, e1501554.

12 L. Pan, H. Huang, M. Zhong and M. Niederberger, Energy Storage Materials, 2019, 16, 519.

13 L. Pan, Z.-W. Zhou, Y.-T. Liu and X.-M. Xie, J. Mater. Chem. A, 2018, 6, 7070.

14 L. Pan, Y.-T. Liu, X.-M. Xie, X.-Y. Ye and X.-D. Zhu, Nano Res., 2016, 9, 2057.
15 V. Augustyn, J. Come, M. A. Lowe, J. W. Kim, P.-L. Taberna, S. H. Tolbert, H. D. Abruña, P. Simon and B. Dunn, Nat. Mater., 2013, 12, 518.

16 A. G. Dylla, G. Henkelman and K. J. Stevenson, Acc. Chem. Res., 2013, 46, 1104.

17 S. Nishimura, A. Takagaki and K. Ebitani, Green Chem., 2013, 15, 2026.

18 J. Yu, Q. Wang, D. O'Hare and L. Sun, Chem. Soc. Rev., 2017, 46, 5950 .

19 J. H. Lee, H. J. Lee, S. H. Choi, J. Shin, S.-Y. Chung and J. W. Choi, Adv. Energy Mater., 2018, 8, 1703572.

20 R. Zhao, M. Wang, D. Zhao, H. Li, C. Wang and L. Yin, ACS Energy Lett., 2018, 3, 132.

21 S. Kajiyama, L. Szabova, K. Sodeyama, H. Iinuma, R. Morita, K. Gotoh, Y. Tateyama, M. Okubo and A. Yamada, ACS Nano, 2016, 10, 3334.

22 R. Xu and H. C. Zeng, Chem. Mater., 2003, 15, 2040.

23 M. D. Slater, D. Kim, E. Lee and C. S. Johnson, Adv. Funct. Mater., 2013, 23, 947.

24 D. Lee, Q. X. Xia, J. M. Yun and K. H. Kim, Appl. Surf. Sci., 2018, 433, 16.

25 L. Lai, L. Chen, D. Zhan, L. Sun, J. Liu, S. H. Lim, C. K. Poh, Z. Shen and J. Lin, Carbon, 2011, 49, 3250.

26 P. Verma, P. Maire and P. Novák, Electrochim. Acta, 2010, 55, 6332.

27 X.-l. Huang, X. Zhao, Z.-l. Wang, L.-m. Wang and X.-b. Zhang, J. Mater. Chem., 2012, 22, 3764.

28 Y.-S. He, D.-W. Bai, X. Yang, J. Chen, X.-Z. Liao and Z.-F. Ma, Electrochem. Commun., 2010, 12, 570.

29 M. Okubo, A. Sugahara, S. Kajiyama and A. Yamada, Acc. Chem. Res., 2018, 51, 591.

30 Z.-S. Wu, W. Ren, L. Wen, L. Gao, J. Zhao, Z. Chen, G. Zhou, F. Li and H.-M. Cheng, ACS Nano, 2010, 4, 3187.

31 G. Huang, F. Zhang, X. Du, Y. Qin, D. Yin and L. Wang, ACS Nano, 2015, 9, 1592.

32 C. Yan, G. Chen, X. Zhou, J. Sun and C. Lv, Adv. Funct. Mater., 2016, 26, 1428.

33 Z. Li, X.-Y. Yu and U. Paik, J. Power Sources, 2016, 310, 41.

34 Y. Ma, J. He, Z. Kou, A. M. Elshahawy, Y. Hu, C. Guan, X. Li and J. Wang, Adv. Mater. Interfaces, 2018, 1800222.

35 Z. Le, F. Liu, P. Nie, X. Li, X. Liu, Z. Bian, G. Chen, H. B. Wu and Y. Lu, ACS Nano, 2017, 11, 2952.

36 Y. Liu, N. Zhang, L. Jiao and J. Chen, Adv. Mater., 2015, 27, 6702.

37 D. Larcher, G. Sudant, J.-B. Leriche, Y. Chabre and J.-M. Tarascon, J. Electrochem. Soc., 2002, 149, A234.

38 G. X. Wang, Y. Chen, K. Konstantinov, M. Lindsay, H. K. Liu and S. X. Dou, J. Power Sources, 2002, 109, 142.

39 M. C. Biesinger, B. P. Payne, A. P. Grosvenor, L. W. M. Lau, A. R. Gerson and R. S. C. Smart, Appl. Surf. Sci., 2011, 257, 2717.

40 XPS Reference Table of Elements, https:/xpssimplified.com/ elements/cobalt.php. 